Article

\title{
Thermal and Catalytic Pyrolysis of Dodecanoic Acid on SAPO-5 and Al-MCM-41 Catalysts
}

\author{
Carolina Freitas ${ }^{1}$, Marizania Pereira ${ }^{2}$, Damari Souza ${ }^{2}$, Noyala Fonseca ${ }^{3}$, Emerson Sales ${ }^{1,3}{ }^{10}$, \\ Roger Frety ${ }^{1,3}$, Camila Felix ${ }^{4}$, Aroldo Azevedo Jr. ${ }^{5}$ and Soraia Brandao 1,2,*(D) \\ 1 UFBA-Instituto de Química, Universidade Federal da Bahia, Rua Barão de Jeremoabo, 147, Ondina, \\ Salvador CEP 40170-115, BA, Brazil; carolina.c_freitas@hotmail.com (C.F.); \\ andradesales.emerson@gmail.com (E.S.); ro_fre@hotmail.fr (R.F.) \\ 2 UFBA-Escola Politécnica, Universidade Federal da Bahia, Rua Professor Aristides Novis, 2, Federação, \\ Salvador CEP 40210-630, BA, Brazil; msena.pet@gmail.com (M.P.); damari.eng@hotmail.com (D.S.) \\ 3 LABEC_Laboratório de Bioenergia e Catálise, Escola Politécnica, Universidade Federal da Bahia, \\ Rua Professor Aristides Novis, 2, Federação, Salvador CEP 40210-630,BA, Brazil; noyala_nscf@hotmail.com \\ 4 IFBA-Instituto Federal da Bahia, Rua Vital Brazil, Pitanguinha, s. n, Simões Filho, \\ Salvador CEP 43700-000, BA, Brazil; camila_rib@yahoo.com.br \\ 5 UFRB-Universidade Federal do Recôncavo da Bahia, Av. Centenário, 697, \\ Feira de Santana CEP 44042-280, BA, Brazil; aroldo.ufrb@gmail.com \\ * Correspondence: soraia.ufba@gmail.com; Tel.: +55-71-3283-6882 (ext. 6889)
}

Received: 25 February 2019; Accepted: 27 April 2019; Published: 3 May 2019

check for updates

\begin{abstract}
In this study, dodecanoic acid was decomposed during fast pyrolysis experiments either thermally or in the presence of SAPO-5 and Al-MCM-41catalysts. The catalysts were synthesized by a hydrothermal route and subsequently characterized by XRD, TPD- $\mathrm{NH}_{3}$, and TGA, and dodecanoic acid was characterized by TGA and DSC. Analysis of the post-pyrolysis products was performed online by gas chromatography coupled with mass spectrometry (GC-MS). The results from pyrolysis at $650{ }^{\circ} \mathrm{C}$ indicated that the nature of the catalysts strongly influences the composition of the products. Linear alkenes were standard products for all pyrolysis experiments, but with Al-MCM-41, various alkene isomers with a linear and cyclic structure formed, as well as saturated and aromatic hydrocarbons. As a whole, Al-MCM-41 led to a much higher dodecanoic acid conversion and higher deoxygenation than SAPO-5. As these catalysts present small differences in strong acid site density, the difference in the global conversion of dodecanoic acid could be attributed to textural characteristics such as pore volume and surface area. In this case, the textural properties of the SAPO-5 are much lower when compared to Al-MCM-41 and, due to a lower accessibility of the reactant molecule to the acidic sites of SAPO-5, partially blocked for fatty acid molecules by the considerable amount of amorphous material, as detected by XRD.
\end{abstract}

Keywords: fast pyrolysis; SAPO-5; Al-MCM-41; dodecanoic acid

\section{Introduction}

The global energy matrix is still based on non-renewable sources and fossil fuels. The use of these sources generates pollution and emissions of greenhouse gases, leaving environmental problems for future generations. Since the second half of the 20th Century, with oil crises, rising fuel demand, and growing environmental awareness, research into alternative energy sources has grown. Renewable sources are now much favored due to their full availability, biodegradability, and low cost [1].

Vegetable oils have a large amount of triacylglycerides (about 90\%) and a lower amount of free fatty acids, mono-, and di-glycerides (8-10\%). Among the acids present in the various oily compounds, saturated fatty acids, such as palmitic (C16:0) and stearic (C18:0), and unsaturated, such as linoleic 
(C18:2) and oleic (C18:1), are the most common, but other acids, such as lauric (C12:0) and myristic (C14:0), exist in specific oils and fats [2].

Brazil has several sources for the supply of oily compounds, such as soybean (whose predominant fatty acid is linoleic acid), babassu (lauric acid), and animal fat (stearic acid). Research into oils from other biomasses has been carried out, for example, castor oil, palm oil pulp, palm kernel almond, babassu coconut kernel, sunflower seeds, and other raw materials [3]. The country is the fourth largest producer of coconut in the world with almost three million tons of fruit per year, and the State of Bahia is the largest producer. Coconut and coconut oil are relevant natural sources of saturated fats, based mainly on dodecanoic acid (C12:0), also known as lauric acid. Coconut oil is obtained from the pulp of mature fresh coconut (Cocos nucifera L.) and contains more than $80 \%$ of saturated fatty acids, such as caproic, caprylic, capric, lauric, myristic, palmitic, and stearic acids. Coconut oil has a concentration of lauric acid above $40 \%$ [4].

Pyrolysis or thermal cracking of triglycerides is a well-known method for producing renewable fuels (Bressler, Maher). Pyrolysis operates in the absence of external $\mathrm{O}_{2}$, providing high yields in liquids when performed at elevated temperatures $\left(400-600^{\circ} \mathrm{C}\right)$, with vapor residence times lower than $5 \mathrm{~s}$ and heating rates between 10 and $200^{\circ} \mathrm{C} / \mathrm{s}$ [2]. Pyrolysis of triglycerides can be summarized by Reaction 1 :

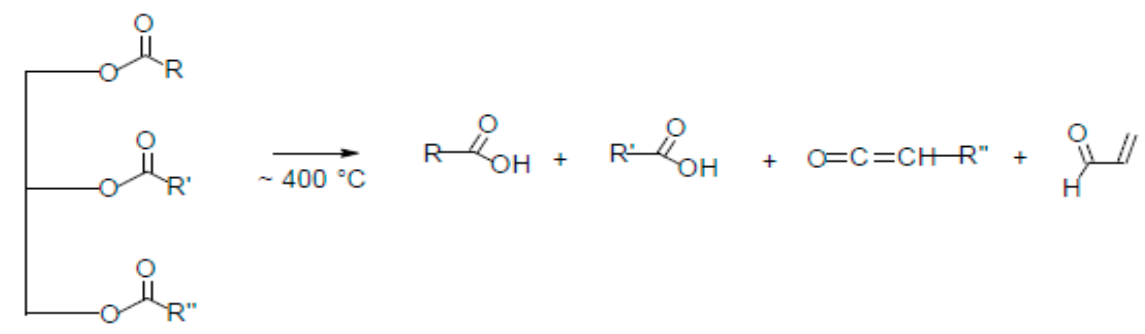

Reaction 1

Thermal cracking produces saturated, unsaturated linear hydrocarbons, or both, via the deoxygenation of carboxylic acids, which can occur through two distinct reaction paths: decarboxylation and decarbonylation. In decarboxylation, the carboxyl group of the fatty acid is removed, forming a saturated hydrocarbon and $\mathrm{CO}_{2}$ (Reaction 2). The decarbonylation consists of the removal of the carbonyl of the fatty acid forming $\mathrm{CO}, \mathrm{H}_{2} \mathrm{O}$, and olefins (Reaction 3) [1].<smiles>[R]C(=O)O</smiles><smiles></smiles>

In addition to the formation of the primary pyrolysis products, many parallel and sequential transformations can occur, leading to a series of oxygenated and deoxygenated molecules with a smaller or higher number of carbon atoms, compared to the initial carbon chains, such as olefins, paraffins, ketones, aldehydes, and aromatics, among others [5].

One way of making pyrolysis more efficient is to promote the reaction in the presence of a suitable catalyst. In recent years, studies dealing with the catalytic conversion of oily biomass feeds, through thermochemical reactions, have reported impressive results, and many reviews have summarized 
the positive and negative aspects of such transformations [6-8]. Further, current research has been done into the use of multi-element and multi-functional catalysts and complex mixtures of feeds in coprocessing strategies [9-12]. However, much essential work is still needed to understand the complexity of the reaction mechanism sequences, and therefore, studies with simpler systems, or model molecules, must be performed.

The interest of the petrochemical and chemical industries in the use of molecular sieves is due to the application of these types of materials in catalytic cracking, isomerization, and alkylation. Molecular sieves have a combination of important properties, such as surface area, large ion exchange capacity, and strong acidity, with high thermal and hydrothermal stability. Due to the regularity of their crystalline channels, molecular sieves allow higher selectivity of the reagents, products, and transition states, on a molecular scale [13]. Catalysts based on molecular sieves with different crystalline structures can induce changes in the product distribution, in the conversion of bio-oils and triglycerides. An example is the several zeolites, such as ZSM-5, Y, and beta, and silicoaluminophosphates studied in bio-oil cracking [3].

The SAPO-5 catalyst has one-dimensional 12-membered straight channel rings. It is a crystalline and microporous material, presenting excellent thermal and hydrothermal stability, and its acidity reaches intermediate values between the zeolite and the AIPO (aluminophosphate molecular sieves). Due to its topology, SAPO-5 provides potential catalytic applications, such as catalytic cracking, isomerization, and alkylation reactions [14].

The molecular sieve MCM-41 belongs to the class of materials known as M41S (Mobil 41 Synthesis). They are Si-based materials with highly-ordered mesopores and a high surface area. MCM-41, consisting of pure silica, presents low acidity. The incorporation of aluminum into the MCM-41 structure increases the number of acid sites, improving catalytic activity [15].

In this work, molecular sieves SAPO- 5 and Al-MCM-41 were synthesized and evaluated as catalysts in the fast pyrolysis of dodecanoic acid, a simple model molecule of fatty compounds. The differences between thermal and catalytic pyrolysis, as well as the distribution of the products formed were analyzed.

\section{Results and Discussion}

Although the textural properties of the present samples were not determined, other samples of SAPO-5 and Al-MCM-41 using the same synthesis procedures have been prepared by some of us. In these cases, surface areas of SAPO-5 and Al-MCM-41 ranged from 247-261 and 485-510 m²/g, respectively, whereas pore volumes were in the order of 0.19 and $0.85 \mathrm{~cm}^{3} / \mathrm{g}$, respectively. Therefore, Al-MCM-41 presented a higher surface area and a much larger pore volume than SAPO-5 [16].

\subsection{X-ray Diffraction}

Figure 1a shows the diffractogram of the SAPO- 5 molecular sieve. The material presented a characteristic diffractogram of the AFI structure, similar to that found in the literature [17]. The presence of the intense halo at about $2 \theta=15-35^{\circ}$ was associated with some extra frame silica.

The diffractogram of the Al-MCM-41 catalyst shown in Figure $1 \mathrm{~b}$ presented a strong reflection at $2 \theta=2.1^{\circ}$, characteristic of the MCM-41 structure. The two peaks of lower intensity and greater width observed at $2 \theta=3-4^{\circ}$ suggest a loss of homogeneity and hexagonal symmetry of the crystalline structure due to the incorporation of aluminum in the structure of MCM-41 [18-20]. 


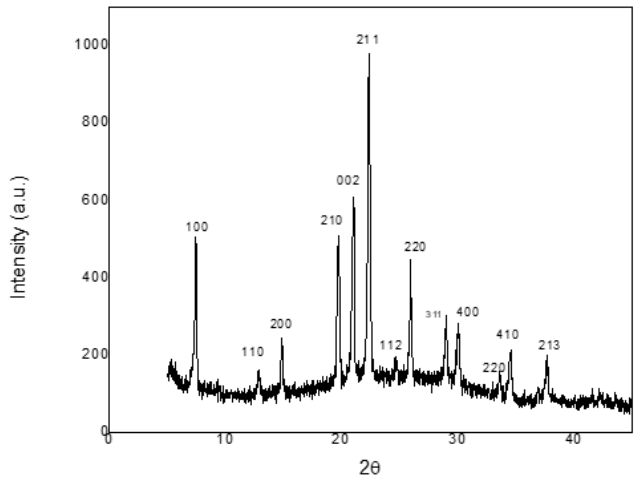

(a)

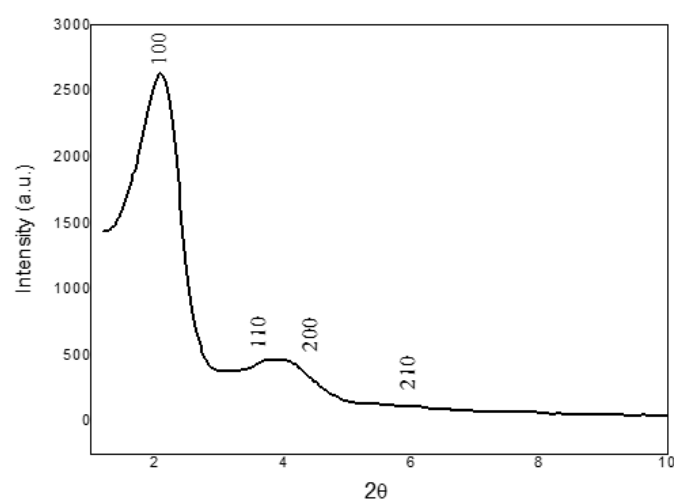

(b)

Figure 1. X-ray diffraction of SAPO-5 (a); X-ray diffraction of Al-MCM-41 (b)

\subsection{Thermodesorption of Ammonia}

Thermodesorption (TPD) of ammonia is often used to estimate the acidity of the molecular sieves and establish strong correlations both for the extent of the reactions and product selectivity [21]. TPD-NH $\mathrm{N}_{3}$ profiles of the SAPO-5 and Al-MCM-41 catalysts in Figure 2a,b, respectively, are generally divided into three temperature ranges: (i) below $300^{\circ} \mathrm{C}$ is associated with weak acid sites; (ii) between 300 and $500{ }^{\circ} \mathrm{C}$ with acidic sites of moderate strength; and (iii) above $500^{\circ} \mathrm{C}$ corresponding to strong acid sites [22].

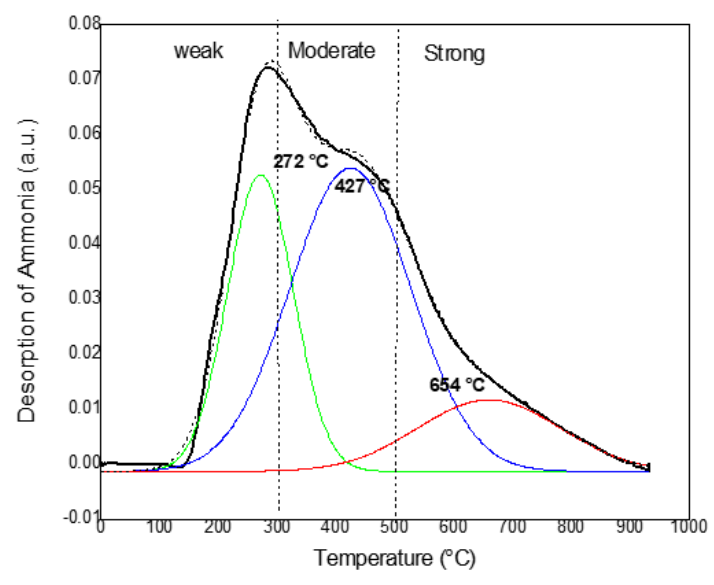

(a)

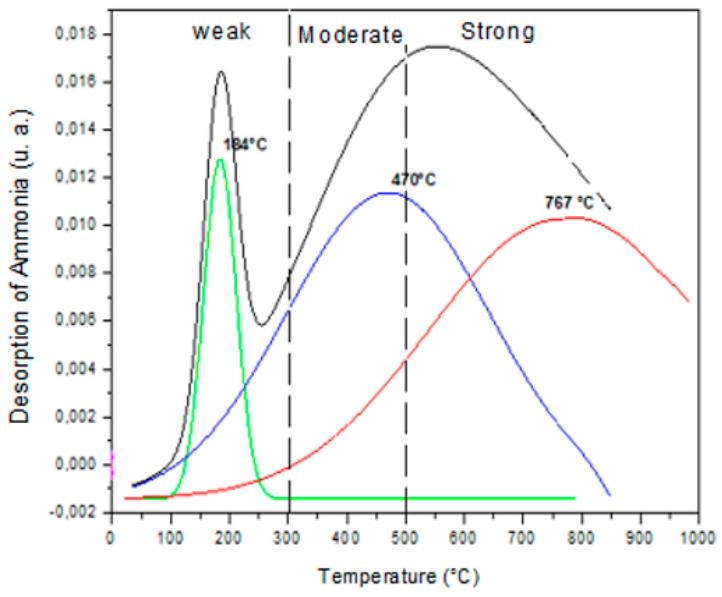

(b)

Figure 2. TPD ammonia analysis of SAPO-5 (a); TPD ammonia analysis of Al-MCM-41(b).

Table 1 presents the concentrations, in $\mathrm{mmol} / \mathrm{g}$, of the acid sites derived from the deconvolution of the experimental $\mathrm{NH}_{3}$ thermodesorption curves, using a Gaussian distribution function.

Table 1. Concentration $\left(\times 10^{-2} \mathrm{mmol} / \mathrm{g}\right)$ of SAPO- 5 and Al-MCM-41 acid sites.

\begin{tabular}{cccc}
\hline Catalysts & Weak & Moderate & Strong \\
\hline SAPO-5 & 1.04 & 1.94 & 0.54 \\
Al-MCM-41 & 0.11 & 0.55 & 0.41 \\
\hline
\end{tabular}

For the SAPO- 5 catalyst, there was a predominance of weak and moderate acid sites with maximum desorption temperature respectively at $272{ }^{\circ} \mathrm{C}$ and $427^{\circ} \mathrm{C}$, in addition to the presence of a peak ascribed to strong acid sites, at a temperature of $654{ }^{\circ} \mathrm{C}$, with a lower concentration. Al-MCM-41 had three desorption peaks at maximum temperatures of $184^{\circ} \mathrm{C}, 470{ }^{\circ} \mathrm{C}$, and $767^{\circ} \mathrm{C}$, respectively. 
The highest concentration, in $\mathrm{mmol} / \mathrm{g}$, found for the Al-MCM-41 catalyst was for moderate acid sites. The desorption peak at a low temperature $\left(<300^{\circ} \mathrm{C}\right)$ probably refers to weak Brønsted acid sites, which are bound to aluminum with tetrahedral coordination $\left(\mathrm{AlO}^{4-}\right)$. Thus, a high temperature $\left(>500{ }^{\circ} \mathrm{C}\right)$ desorption may be ascribed to ammonia adsorbed in Lewis acid sites on the surface of the molecular sieve, created by the dehydroxylation of the aluminum atoms substituting silicon atoms in the structure $[21,22]$.

\subsection{Thermogravimetric Analysis}

The profiles of the thermogravimetric analysis curves of the Al-MCM- 41 and SAPO- 5 samples are shown respectively in Figure 3a,b.

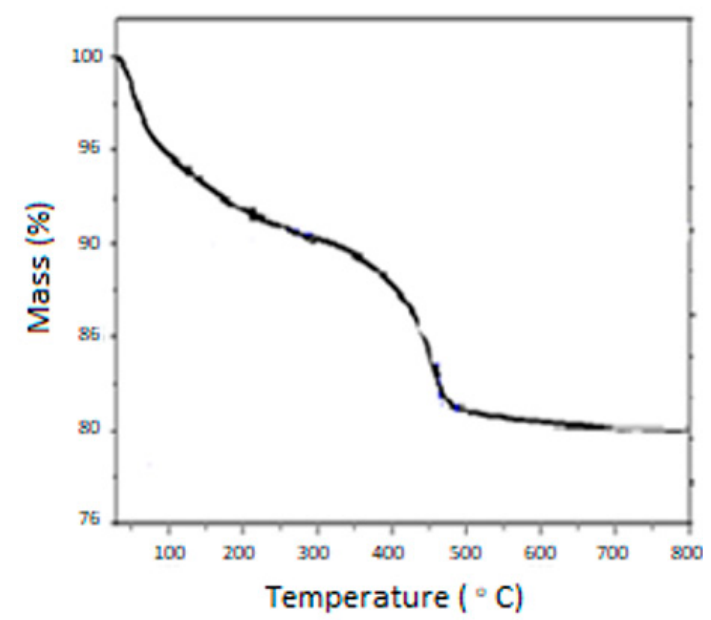

(a)

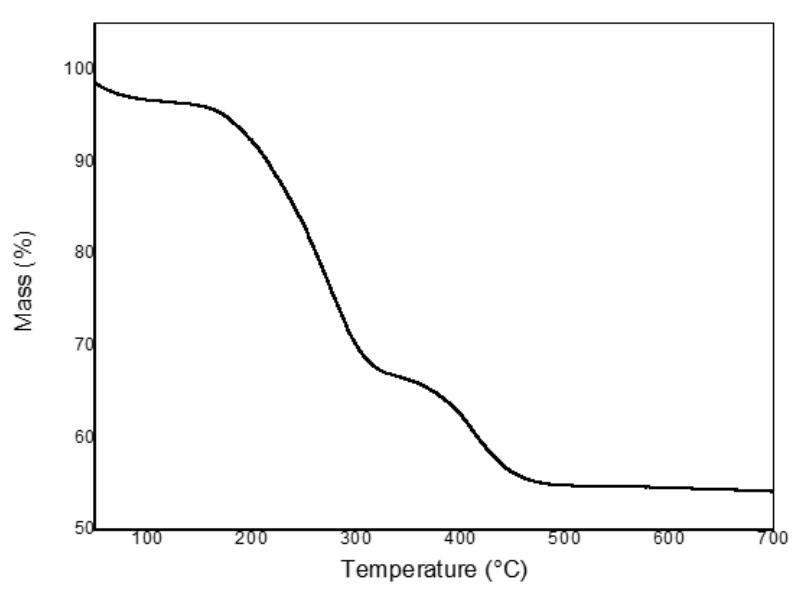

(b)

Figure 3. TGA profile of SAPO-5 catalyst (a); TGA profile of Al-MCM-41 catalyst (b).

In Figure 3a, the thermogravimetric analysis of the SAPO- 5 catalyst is presented, in which three regions of mass loss can be observed. The first $8 \%$ mass loss event, from room temperature up to $200^{\circ} \mathrm{C}$, was associated with the desorption of adsorbed water on the outer surface and occluded in the pores. The second step had a loss of $10 \%$ in the range of $200{ }^{\circ} \mathrm{C}-470{ }^{\circ} \mathrm{C}$, with a maximum rate from $440{ }^{\circ} \mathrm{C}-470{ }^{\circ} \mathrm{C}$, which was ascribed to the desorption of triethylamine (template) occluded in the channels. Finally, the third region, between 470 and $750{ }^{\circ} \mathrm{C}$, with a loss of $2 \%$, was related to the desorption of the occluded channel surfactant and to the decomposition of the protonated amine $\left(\mathrm{TEA}^{+}\right)[23]$.

In Figure $3 \mathrm{~b}$, the first mass loss event $(2 \%)$ was related to the loss of water physically adsorbed in the pores of the Al-MCM-41 catalyst. The second mass loss event (33\%) was attributed to the degradation of the organic molecules of the template CTMABr (hexadecyltrimethylammonium bromide). The third event $(10 \%)$ was associated with the removal of the residual template and also water resulting from the secondary condensation of the silanol groups, according to the literature [24,25].

The TGA/DTG curves of pure lauric acid, Figure 4, exhibited a region of significant mass loss (95\%) between $150{ }^{\circ} \mathrm{C}$ and $250{ }^{\circ} \mathrm{C}$, followed by small mass losses up to $600{ }^{\circ} \mathrm{C}$. The excessive loss of mass was attributed to the volatilization of lauric acid and the losses at higher temperatures to progressive degradation of non-volatile residues. 


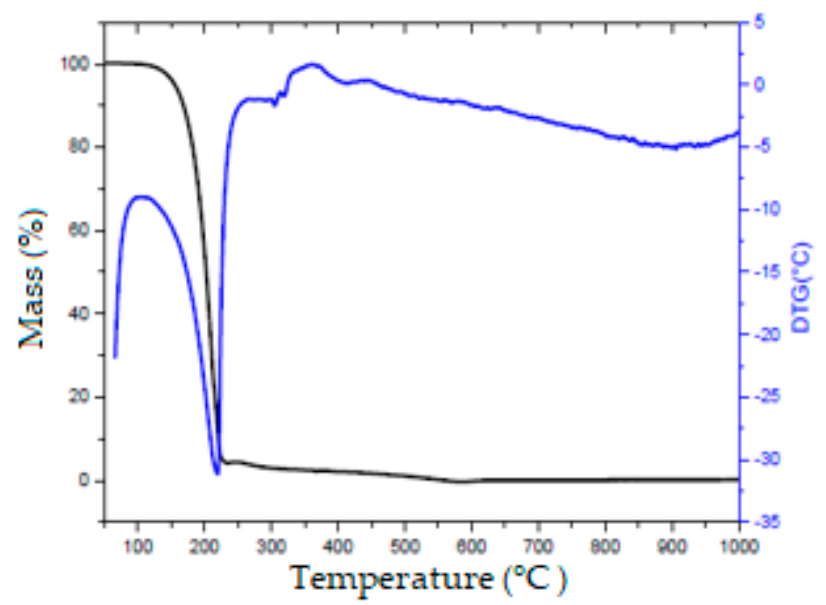

Figure 4. TGA/DTG profile of lauric acid.

\subsection{Differential Scanning Calorimetry}

The DSC profile of pure lauric acid, Figure 5, shows a succession of endothermic and exothermic events. The endothermic phenomenon appearing at around $50{ }^{\circ} \mathrm{C}$, not associated with mass loss, according to Figure 4, was related to the fusion of lauric acid. At about $200{ }^{\circ} \mathrm{C}$, a second weak endothermal phenomenon was observed, probably related to the initial volatilization of lauric acid, quickly followed by an exothermic event linked to the processes of cracking and autoxidation, possibly associated with the degradation of the fatty acid. The results obtained by the DSC and TGA/DTG analyses suggest that the lauric acid was fully converted to the vapor phase below $250{ }^{\circ} \mathrm{C}$ and transformed into products between 250 and $600{ }^{\circ} \mathrm{C}$.

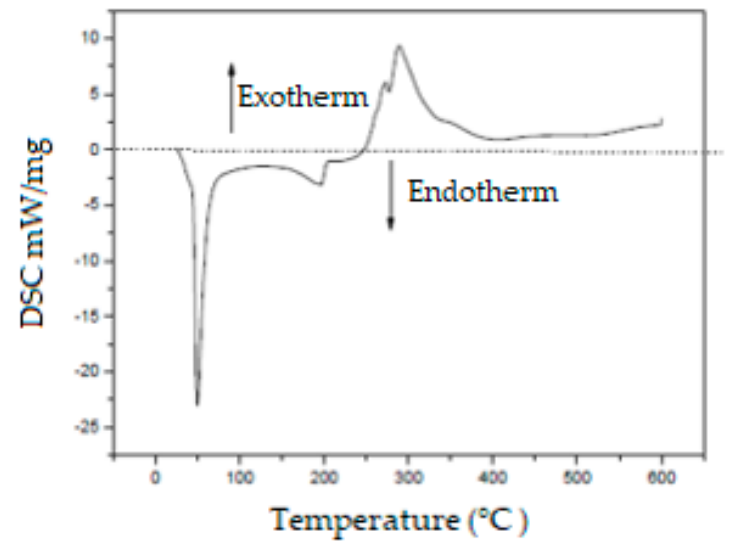

Figure 5. DSC profile of lauric acid.

\subsection{Fast Pyrolysis Reaction}

The fast pyrolysis experiments with pure lauric acid and lauric acid adsorbed on both molecular sieve catalysts was performed at $650{ }^{\circ} \mathrm{C}$ under helium flow and with an estimated heating rate of $1000{ }^{\circ} \mathrm{C} \mathrm{s}^{-1}$. The global results of the products obtained from thermal and thermo-catalytic pyrolysis are shown in Figures 6-8. The deoxygenated compounds were grouped into different product families to facilitate the analysis of the products. The remaining reactant is also indicated in Figures 6 and 7 , as the observed conversions were $9 \%$ and $12 \%$, respectively. When using the Al-MCM-41 catalyst (Figure 8), no lauric acid was detected after pyrolysis, indicating a total conversion. 


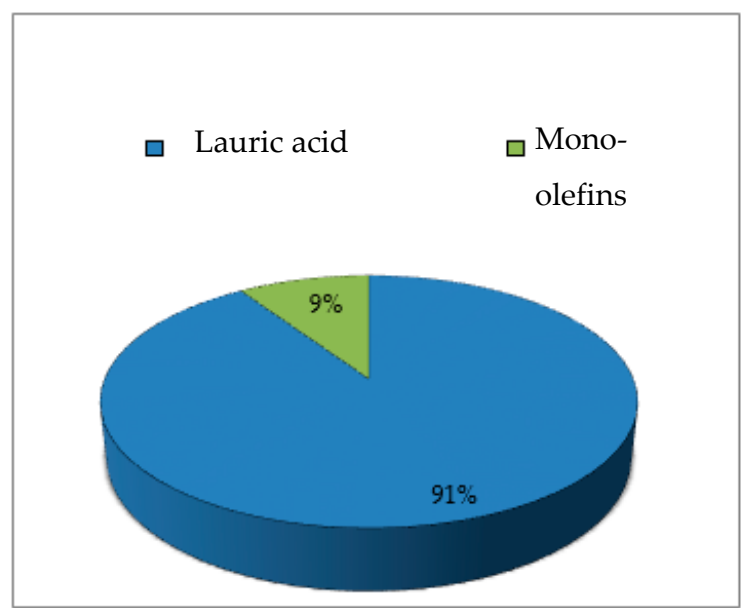

Figure 6. Compounds identified after fast pyrolysis of pure lauric acid at $650{ }^{\circ} \mathrm{C}$.

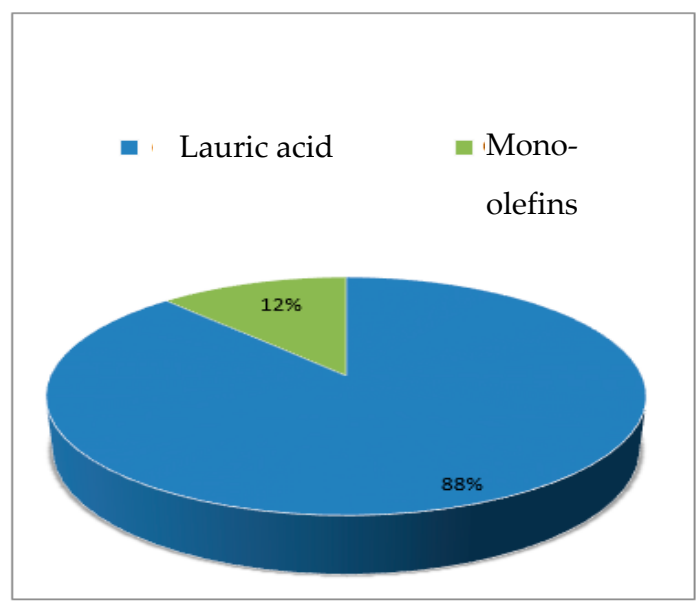

Figure 7. Compounds identified after fast pyrolysis of lauric acid at $650{ }^{\circ} \mathrm{C}$ in the presence of SAPO-5.

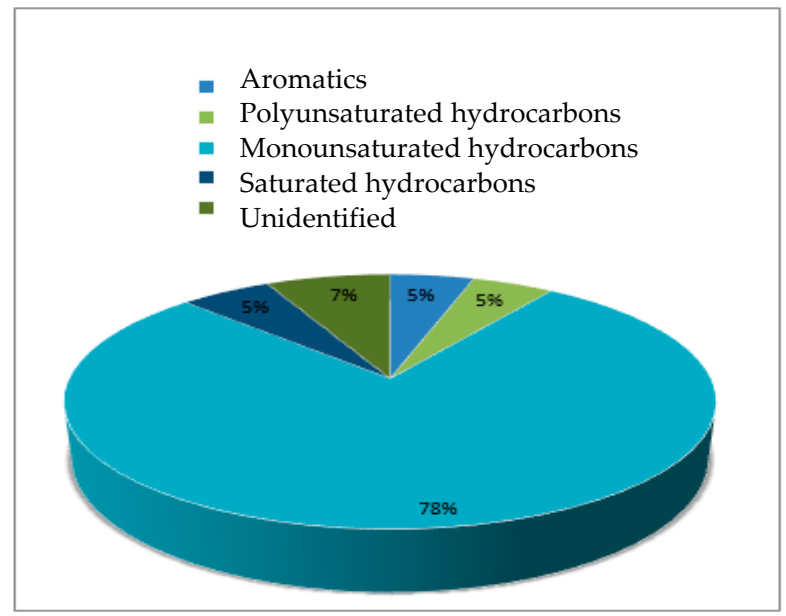

Figure 8. The yield of fast pyrolysis products of lauric acid at $650{ }^{\circ} \mathrm{C}$ in the presence of Al-MCM- 41 .

In thermal pyrolysis, limited deoxygenation of lauric acid occurs via the decarbonylation route, mainly giving $\alpha$-olefins $\left(\mathrm{C}_{3}\right.$ to $\left.\mathrm{C}_{11}\right)$ [8], as observed in Figure 6. Pyrolysis of fatty acids can proceed through the breaking of C-C and C-O bonds. Two competing routes can explain the presence of products with fewer than ten carbon atoms: (i) deoxygenation of the starting acid, followed by breaking of the $\mathrm{C}-\mathrm{C}$ bond to produce hydrocarbon radicals; and (ii) cracking of the $\mathrm{C}-\mathrm{C}$ bond of the chain, 
followed by deoxygenation of a shorter chain carboxylic acid. With saturated compounds, such as lauric acid, the first route is favored [16,24].

In the catalytic pyrolysis of the acid adsorbed on SAPO-5 (Figure 7), a slightly larger number of $\alpha$-olefins (from $C_{3}-C_{11}$ ) were formed, which consisted of potential feedstock to produce high octane gasoline. A similar study with the same catalyst (SAPO-5), using palmitic acid, i.e., a saturated fatty acid with a carbon chain longer than lauric acid, can be found in [16]. In both cases, the pyrolysis products presented great similarity since they showed a high distribution of linear mono-unsaturated hydrocarbons.

For pyrolysis of lauric acid in the presence of Al-MCM-41 catalysts (Figure 8), $\mathrm{C}_{3}-\mathrm{C}_{11}$ olefins (68\%) including isomers with internal $\mathrm{C}=\mathrm{C}$ bonds, both in cis and trans configuration, cyclic mono-unsaturated molecules, and methylated molecules, were identified. Cyclic and alkylated cyclic saturated products (14\%) and aliphatic alkanes (4\%), together with mono-aromatics (benzene, toluene, and p-xylene) $(4 \%)$, were also found. The formation of both aromatic and saturated products can be attributed to the acidity of the Al-MCM-41 catalyst, which should promote hydrogen transfer reactions. The hydrogen liberated during aromatic formation could be in part used to saturate olefin-based products and possibly helped the alkylation reaction.

Figure 9 presents the normalized distribution of the $\alpha$-olefins obtained (an area greater than $0.5 \%$ of the total area) after thermal pyrolysis of lauric acid at $650{ }^{\circ} \mathrm{C}$ and catalytic pyrolysis of lauric acid with SAPO- 5 at the same temperature. The SAPO- 5 catalyst did not alter the distribution of the products significantly, compared to the thermal pyrolysis. Only the conversion was slightly higher $(12 \%$ and $9 \%$, as seen in Figures 6 and 7$)$, which is not visible in the figure because of normalization.

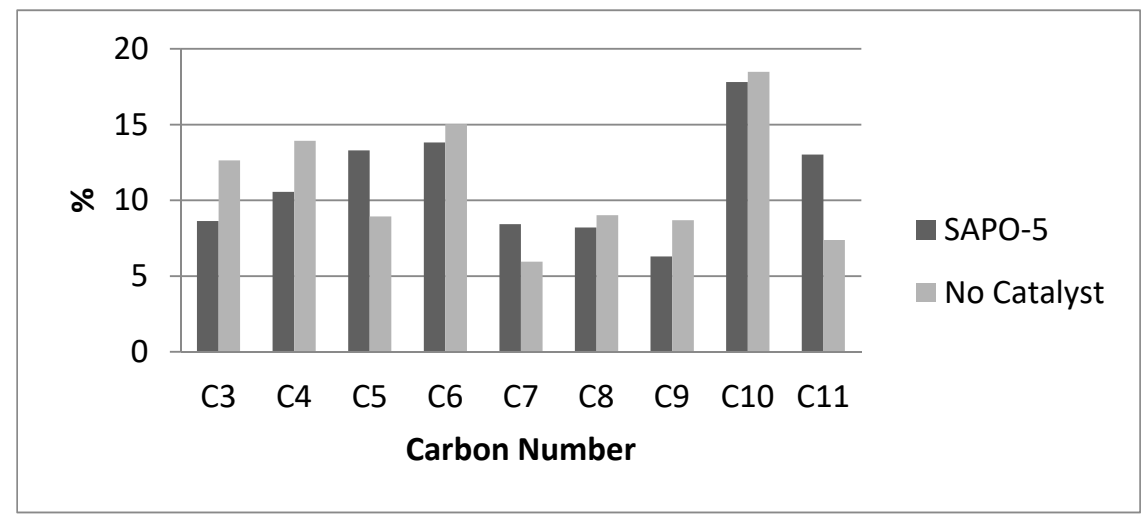

Figure 9. Normalized distribution of the $\alpha$-olefins obtained after pyrolysis of lauric acid at $650{ }^{\circ} \mathrm{C}$ :

(匹) SAPO-5 catalyst and ( $\square$ ) no catalyst.

Table 2 presents the C6 ( 6 isomers) and C11 (13 isomers) olefins identified after dodecanoic acid pyrolysis at $650{ }^{\circ} \mathrm{C}$ in the presence of Al-MCM-41, limiting the identification of the products to those with a relative area greater than $0.5 \%$ of the pyrogram total area. Among the main products, linear, cyclic, and alkylated olefins were identified, as well as cis and trans isomers.

When considering the complete family of monounsaturated molecules obtained in the presence of Al-MCM-41, represented in Figure 10, the amount of isomers does not increase continuously with chain length; $\mathrm{C}_{8}$ olefins have both a lower number of identified isomers (two) and the most moderate content. It suggests a potential application for gasoline and kerosene fuels, after partial hydrogenation. 
Table 2. $\mathrm{C}_{6}$ and $\mathrm{C}_{11}$ mono-unsaturated main products observed during dodecanoic acid pyrolysis at $650{ }^{\circ} \mathrm{C}$ using Al-MCM-41 catalyst.

\begin{tabular}{ccc}
\hline Carbon Number & Retention Time (min) & Mono-Unsaturated \\
\hline \multirow{2}{*}{ C6 } & 1.686 & 2-Pentene, 4-methyl- \\
& 1.785 & 1-Hexene \\
& 1.883 & 3-Hexene, (E)- \\
1.918 & 3-Hexene, (Z)- \\
1.995 & 2-Pentene, 3-methyl-, (Z)- \\
2.268 & Cyclopentene, 1-methyl- \\
\hline 8.383 & 4-Decene, 3-methyl-, (E)- \\
8.426 & 2-Decene, 4-methyl-, (Z)- \\
8.538 & 5-Undecene, (E)- \\
8.608 & 4-Undecene, (Z)- \\
8.671 & 2-Decene, 7-methyl-, (Z)- \\
8.699 & 5-Undecene, (Z)- \\
8.769 & 1-Decene, 5-methyl- \\
& 8.825 & 4-Undecene, (e)- \\
& 8.846 & 2-Decene, 6-methyl-, (Z)- \\
& 8.916 & 3-Undecene, (Z)- \\
& 8.973 & 3-Undecene, (E)- \\
& 9.064 & 2-Undecene, (Z)- \\
& 9.169 & 2-Undecene, (E)- \\
\hline
\end{tabular}

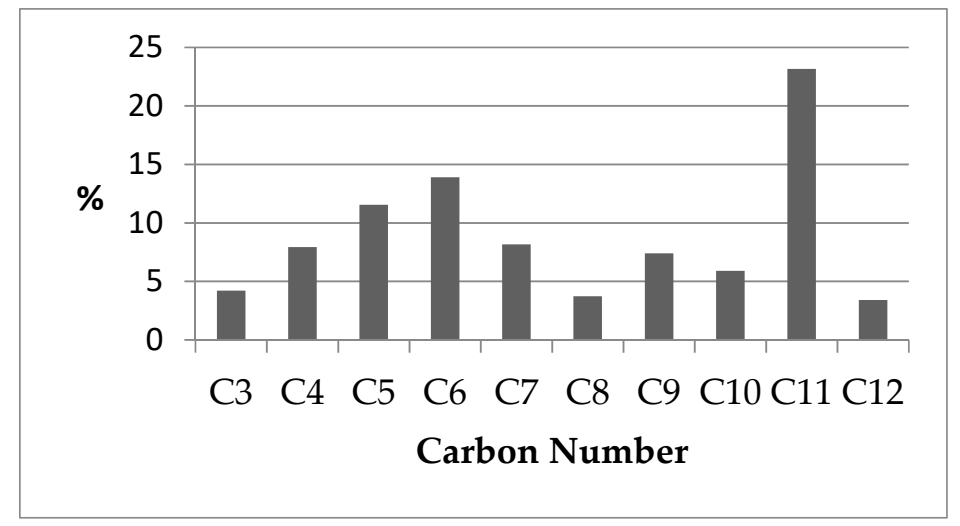

Figure 10. Mono-unsaturated isomers' distribution from pyrolysis of lauric acid at $650{ }^{\circ} \mathrm{C}$, in the presence of Al-MCM-41.

\subsection{Comparison between the SAPO-5 and Al-MCM-41 Catalytic Behavior}

The extent of lauric acid conversion between the three pyrolysis reactions was different: $9 \%$ was observed during thermal pyrolysis, $12 \%$ when lauric acid was adsorbed on the SAPO- 5 catalyst, and about $100 \%$ when the fatty acid was adsorbed on Al-MCM- 41 catalyst. The results are consistent and close to those found in the literature regarding the pyrolysis of saturated fatty acids [4]. However, the results obtained for pyrolysis of unsaturated fatty acids on Al-MCM-41-based catalyst, similar to those in the present work, showed that deoxygenation was not as effective as for saturated acids [19].

An essential point of the discussion is linked to the low conversion of lauric acid observed when using SAPO-5 catalyst compared to Al-MCM-41. The TPD of $\mathrm{NH}_{3}$ profiles are different for these two catalysts, but small differences in the number of strong acid sites were observed; this alone cannot explain the significant differences in conversion between both molecular sieves. Specific surface area and pore volume of SAPO- 5 were much lower than the values for Al-MCM-41. Moreover, a large amount of amorphous material in SAPO- 5 was revealed by XRD analysis, and this can cause lower accessibility of the dodecanoic acid molecule to acid sites in SAPO- 5 catalyst. These two last characteristics are probably responsible for the observed differences in performances between both 
catalysts. The access of large lauric acid molecules to the acidic sites located inside the porous structure of SAPO- 5 could be limited for two main reasons: (i) a lower mean diameter of SAPO-5 pores compared to that of Al-MCM-41; (ii) the pore mouth in SAPO-5 can be partially blocked by the amorphous species. In other words, only a small proportion of SAPO- 5 can interact with dodecanoic acid, limiting the conversion of the fatty acid during pyrolysis experiments.

\section{Materials and Methods}

\subsection{Catalyst Preparation}

The synthesis of the SAPO-5 catalyst was carried out following the methodology found in [4], and some modifications were made to adjust the $\mathrm{Si} / \mathrm{Al}$ ratio. Pseudoboehmite and orthophosphoric acid ( $85 \%$, Sigma-Aldrich) were used as sources of $\mathrm{Si}$ and $\mathrm{P}$, respectively. Then, the triethylamine (Sigma-Aldrich, St. Louis, MO, USA) template was added to tetraethyl orthosilicate (98\%, Sigma-Aldrich, St. Louis, MO, USA) and the surfactant hexadecyltrimethylammonium bromide (Sigma-Aldrich, St. Louis, MO, USA), in solution with hexanol (Sigma-Aldrich, St. Louis, MO, USA). Initially, $19.56 \mathrm{~mL}$ of orthophosphoric acid (previously diluted in $20 \mathrm{~mL}$ of deionized water) were placed in a beaker containing $22.4 \mathrm{~g}$ of pseudoboehmite (dispersed in $63 \mathrm{~mL}$ of $\mathrm{H}_{2} \mathrm{O}$ ); this system was kept under stirring for two hours. After that, $38.64 \mathrm{~mL}$ of triethylamine were added, and stirring was continued for a further two hours. After this time, a solution prepared by the addition of $4.82 \mathrm{~mL}$ of TEOS (Tetraethyl Orthosilicate) $+78.82 \mathrm{~mL}$ of hexanol $+3.8 \mathrm{~g}$ of CTMABr (hexadecyltrimethylammonium bromide) was added and again stirred for another two hours. The mixture was partitioned into autoclaves and put into an oven preheated to $170^{\circ} \mathrm{C}$, where it remained for $24 \mathrm{~h}$. The material obtained after this period was centrifuged, washed with alcohol and distilled water, respectively, and again routed to a drying oven at $100^{\circ} \mathrm{C}$ for six hours.

A sample of Al-MCM-41 with a silica/alumina (SAR) ratio of 60 was prepared. Commercial silica (Aerosil 200) and sodium aluminate were used as sources of $\mathrm{Si}$ and $\mathrm{Al}$, respectively. As a guideline of the mesoporous structure, hexadecyltrimethylammonium bromide (CTMABr) was used in the form of $25 \% w / w$ aqueous solution. Sodium hydroxide solution $(50 \% w / w)$ was used to maintain the basic $\mathrm{pH}$. The molar composition of the synthesis gel was: $1 \mathrm{SiO}_{2}: 0.025 \mathrm{Al}_{2} \mathrm{O}_{3}: 0.08 \mathrm{Na}_{2} \mathrm{O}: 0.3$ CTMA: $26 \mathrm{H}_{2} \mathrm{O}$.

The samples were prepared from suspensions and solutions named as A, B, C. In Suspension A, $20.2 \mathrm{~g}$ of silica $\left(\mathrm{SiO}_{2}\right)$ were mixed in $38.3 \mathrm{~g}$ of distilled water. For Solution $\mathrm{B}, 2.8 \mathrm{~g}$ of sodium hydroxide $(\mathrm{NaOH})$ were added to $2.8 \mathrm{~g}$ of distilled water, and in Solution $\mathrm{C}, 36.8 \mathrm{~g}$ of hexadecyltrimethylammonium bromide (CTMABr) were dissolved in $110.5 \mathrm{~g}$ of distilled water.

In Solution B, the amount of $0.9 \mathrm{~g}$ of sodium aluminate and then Solution $\mathrm{C}$ were added under vigorous and constant stirring until complete dissolution of the sodium aluminate. Solution A was then added under vigorous stirring at room temperature. The mixture was then placed in autoclaves without stirring and heated at $150{ }^{\circ} \mathrm{C}$ for $48 \mathrm{~h}$.

Then were added $0.9 \mathrm{~g}$ of sodium aluminate to Solution B and then Solution C added under vigorous and constant stirring until complete dissolution of the sodium aluminate. Suspension A was submitted to vigorous stirring at room temperature. The mixture was then placed in autoclaves without stirring and heated at $150^{\circ} \mathrm{C}$ for $48 \mathrm{~h}$.

After this procedure, the product was washed with distilled water separated using a centrifuge and oven dried at $100{ }^{\circ} \mathrm{C}$ for $4 \mathrm{~h}$. After this step, the material was calcined to remove the remaining template in the porous structure.

Al-MCM-41 catalyst was calcined under an inert atmosphere $\left(\mathrm{N}_{2}, 30 \mathrm{~mL} / \mathrm{min}\right)$ to $370{ }^{\circ} \mathrm{C}$ for $1 \mathrm{~h}$ $30 \mathrm{~min}$ to remove the remaining template in the porous structure. After this step, the $\mathrm{N}_{2}$ flux was replaced by a synthetic air flow $(30 \mathrm{~mL} / \mathrm{min})$ maintaining the temperature of $550{ }^{\circ} \mathrm{C}$ for over ten hours for remaining burning of the template.

The SAPO- 5 catalyst was calcined in an inert atmosphere $\left(\mathrm{N}_{2}, 100 \mathrm{~mL} / \mathrm{min}\right)$ to $450{ }^{\circ} \mathrm{C}\left(10^{\circ} \mathrm{C} / \mathrm{min}\right)$, remaining for one hour at this temperature, to remove the remaining template in the structure. After 
this stage, the $\mathrm{N}_{2}$ was replaced by synthetic air $(100 \mathrm{~mL} / \mathrm{min})$, maintained at a temperature of $550{ }^{\circ} \mathrm{C}$ for $5 \mathrm{~h}$ to burn the coke formed with the decomposition of the template.

\subsection{Catalyst Characterization}

\subsubsection{X-ray Diffraction}

The X-ray diffraction measurements were conducted on a Shimadzu apparatus, model XRD-6000, using $\mathrm{Cu} \mathrm{K} \alpha$ radiation $(\lambda=1.5418 \AA$ ) (Shimadzu, Kobe, Japan). The diffractograms were collected in a range from $1-50^{\circ}$, with a scanning speed of $0.25^{\circ} \mathrm{min}^{-1}$. They were obtained at a constant power source of $40 \mathrm{kV}$ and $30 \mathrm{~mA}$, at room temperature. The powder samples were analyzed without any previous treatment.

\subsubsection{Temperature Programmed Desorption of Ammonia (TPD- $\mathrm{NH}_{3}$ )}

The measurement of the density and strength of the acid sites of the samples was carried out using the temperature programmed desorption (TPD- $\mathrm{NH}_{3}$ ). Initially, the ammonia was adsorbed at room temperature for $1 \mathrm{~h}$. The samples were then heated at a rate of $10^{\circ} \mathrm{C} / \mathrm{min}$ to $150^{\circ} \mathrm{C}$ for $1 \mathrm{~h}$ under $\mathrm{He}$ flow to remove the poorly-adsorbed molecules. The ammonia desorption step was performed under a constant helium flow of $25 \mathrm{~mL} / \mathrm{min}$ to $700{ }^{\circ} \mathrm{C}$, using a heating rate of $10^{\circ} \mathrm{C} / \mathrm{min}$. The equipment used was the Chemisorb 2720, Pulse Chemisorption System, Micromeritics, equipped with a thermal conductivity detector (TCD), a quartz reactor, and gas supply system.

\subsubsection{Thermogravimetric Analysis}

The samples ( $2 \mathrm{mg}$ of mass) were heated with a temperature ramp of $10^{\circ} \mathrm{C} / \mathrm{min}$ from ambient temperature to $1000{ }^{\circ} \mathrm{C}$ in a Shimadzu apparatus, Model TGA-50 (Shimadzu, Kobe, Japan), under a constant flow of $50 \mathrm{~mL} / \mathrm{min}$ of nitrogen.

\subsection{Catalytic Test}

The pyrolysis experiments were performed on a multi-shot pyrolyzer model EGA/PY-3030D (Frontier Laboratories LTD, Fukushima, JPN) connected online with a GC-MS-5799 (Agilent, Santa Clara, CA, USA). In the thermal fast pyrolysis, 1.1 milligrams of pure lauric acid were used, whereas in the catalytic pyrolysis tests, $1.1 \mathrm{mg}$ of the lauric acid/catalyst mixture were used.

The mixture of the lauric acid with the catalyst was carried out with the addition of the fatty acid to the catalyst in the proportion $1: 10(\mathrm{~m} / \mathrm{m})$, by mechanical mixing. Subsequently, the mixture was heated to $60^{\circ} \mathrm{C}$, a temperature higher than the melting point of lauric acid $\left(43^{\circ} \mathrm{C}\right)$, and continuously homogenized. This treatment allowed the lauric acid to migrate inside the pores of the catalysts. After this step, the mixture still in powder form was stored away from moisture, then added to the titanium sample holder, and covered with quartz wool.

The samples were dropped by gravity into the pyrolysis furnace preheated to $650{ }^{\circ} \mathrm{C}$ under a helium atmosphere and remained under these conditions for $20 \mathrm{~s}$ before an aliquot of the gaseous atmosphere was introduced into the analytical system. For the chromatographic analysis of the products, an HP-5MS column was used with a heating ramp comprising an initial temperature of $40^{\circ} \mathrm{C}$ for 3 minutes, followed by a ramp of $20^{\circ} \mathrm{C} / \mathrm{min}$ to $320^{\circ} \mathrm{C}$, with the temperature maintained for $20 \mathrm{~min}$. The rate of helium flow through the column was $2 \mathrm{~mL} / \mathrm{min}$. The temperature of the pyrolyzer interface was $320^{\circ} \mathrm{C}$. The products obtained by GC/MS were identified based on the retention times and by comparison with the standard mass spectral fragments of the National Institute of Standards and Testing database.

\section{Concluding Remarks}

The presence of the catalysts modified the quantity and distribution of the products. The fast pyrolysis in the presence of catalysts based on mesoporous and microporous molecular sieves allowed 
the production of olefins in the gasoline range. Using both thermal and catalytic pyrolysis with the SAPO- 5 catalyst, the conversion of dodecanoic acid was limited, $9 \%$ and $12 \%$, respectively, and the main products were terminal olefins $\left(\mathrm{C}_{3}-\mathrm{C}_{11}\right)$. In the presence of the Al-MCM- 41 catalyst, the total conversion of the lauric acid was observed, and the main products were internal and alkylated olefins, fundamental for both chemical and petrochemical industries.

Author Contributions: S.B. has conceived the project, funding acquisition, designed the experiments, analyzed the data and written the paper. C.F. (Carolina Freitas), M.P., D.S. and N.F. have designed and performed the experiments, analyzed the data and written the paper. E.S., R.F., C.F. (Camila Felix) and A.A.J. have designed the experiments, analyzed the data and written the paper.

Funding: FAPESB (Bahia Research Foundation), project DTE 0043/2011, and CNPq, project 552367/2011-7 funded this research.

Acknowledgments: The authors are grateful to CNPq, FAPESB, and CAPES for scholarships and financial support.

Conflicts of Interest: The authors declare no conflict of interest.

\section{References}

1. De M. Araújo, A.M.; de O. Lima, R.; Gondim, A.D.; Diniz, J.; Di Souza, L.; de Araujo, A.S. Thermal and catalytic pyrolysis of sunflower oil using AlMCM-41. Renew. Energy 2017, 101, 900-906.

2. Badoga, S.; Ganesan, A.; Dalai, A.K.; Chand, S. Effect of synthesis technique on the activity of CoNiMo tri-metallic catalyst for hydrotreating of heavy gas oil. Catal. Today 2017, 291, 160-171. [CrossRef]

3. Rodrigues, T.O.; Rousset, P.; do Vale, A.T.; Broust, F. Bioóleo: Uma Alternativa para Valorização Energética da Biomassa. Rev. Bras. Energ. 2011, 17, 39-56.

4. Maher, K.D.; Bressler, D.C. Pyrolysis of Triglyceride Materials for the Production of Renewable Fuels and Chemicals. Bioresour. Technol. 2007, 98, 2351-2368. [CrossRef]

5. Wu, P.; Jiang, X.; Jin, Q.; Liu, F.; Zhang, J.; Zhu, Y.; Xia, L.; Shao, T.; Wang, K.; Li, T. Production of jet fuel range biofuels by catalytic transformation of triglycerides based oils. Fuel 2017, 188, 205-211. [CrossRef]

6. Sonthalia, A.; Kumar, N. Hydroprocessed vegetable oil as a fuel for transportation sector: A review. J. Energy Inst. 2019, 82, 1-17. [CrossRef]

7. Bezergianni, S.; Dimitriadis, A.; Kikhtyanin, O.; Kubicka, D. Refinery co-processing of renewable feeds. Prog. Energy Comb. Sci. 2018, 68, 29-64. [CrossRef]

8. Kubicka, D.; Kikhtyanin, O. Opportunities for zeolites in biomass up-grading: Lessons from the refining and petrochemical industry. Catal. Today 2015, 243, 10-22. [CrossRef]

9. Merdun, H.; Sezgin, I.V. Products distribution of catalytic co-pyrolysis of greenhouse vegetable waste and coal. Energy 2018, 162, 953-963. [CrossRef]

10. Jahromi, H.; Agblevor, F.A. Hydrodeoxygenation of Aqueous-Phase Catalytic Pyrolysis Oil to Liquid Hydrocarbons using Multifunctional Nickel catalysts. Ind. Eng. Chem. Res. 2018, 57, 13257-13268. [CrossRef]

11. Castille, A.; Bessette, C.; Thomas, F.; Eternad, M. Sustainable hydrocarbons production via simultaneous condensation-hydrodeoxygenation of propionic acid with furfural over red mud-supported noble metal catalysts. Catal. Commun. 2019, 121, 5-10. [CrossRef]

12. Wang, Y.; Dai, L.; Fan, L.; Cao, L.; Zhou, Y.; Zhao, Y.; Liu, Y.; Ruan, R. Catalytic co-pyrolysis of waste vegetable oil and high density polyethylene for hydrocarbon fuel production. Waste Manag. 2017, 61, $276-282$. [CrossRef]

13. Abdelfattah, M.S.H.; Abu-Elyazeed, O.S.M.; Abdelazeem, M.A. On biodiesels from castor raw oil using catalytic pyrolysis. Energy 2018, 143, 950-960. [CrossRef]

14. Nash, C.P.; Ramanathan, A.; Ruddy, D.A.; Behl, M.; Gjersing, E.; Griffin, M.; Zhu, H.; Subramaniam, B.; Schaidle, J.A.; Hensley, J.E. Mixed alcohol dehydration over Brønsted and Lewis acidic catalysts. Appl. Catal. A Gen. 2016, 510, 110-124. [CrossRef]

15. Karnjanakom, G.; Suriya-umporn, S.; Bayu, T.; Kongparakul, A.; Samart, S.; Fushimi, C.; Abudula, C.; Guan, A. High selectivity and stability of Mg-doped Al-MCM-41 for in-situ catalytic upgrading fast pyrolysis bio-oil. Energy Convers. Manag. 2017, 142, 272-285. [CrossRef] 
16. De Azevedo, A.F., Jr. Desenvolvimento de Catalisadores a Base de SAPO-5 Para Avaliação na Reação de Fast Pirólise de Compostos Graxos. Ph.D. Thesis, Universidade Federal da Bahia (UFBA), Salvador, Brazil, 24 Auguest 2014.

17. Bandyopadhyay, R.; Bandyopadhyay, M.; Kubota, Y.; Sugi, Y. Synthesis of $\mathrm{AlPO}_{4}$ Molecular Sieves with AFI and AEL Structures by Dry-Gel Conversion Method and Catalytic Application of Their SAPO Counterparts on Isopropylation of Biphenyl. J. Porous Mat. 2002, 9, 83-95. [CrossRef]

18. Vieira, S.S. Produção de Biodiesel via Esterificação de Ácidos Graxos Livres Utilizando Catalisadores Heterogêneos Ácidos. Ph.D. Thesis, Universidade Federal de Lavras (UFLA), Lavras, Brazil, 24 February 2011.

19. Yu, F.; Gao, L.; Wang, W.; Zhang, G.; Ji, J. Bio-fuel production from the catalytic pyrolysis of soybean oil over Me-Al-MCM-41 (Me = La, Ni or Fe) mesoporous materials. J. Anal. Appl. Pyrolysis 2013, 104, 325-329. [CrossRef]

20. Barbosa, F.A.; dos Santos, A.C.B.; da Silva, M.I.P.; Stumbo, A.M. Resistance to poisoning by nitrogen compounds of NiMo/Al-MCM-41 hydrocracking catalysts. Catal. Today 2004, 98, 109-113. [CrossRef]

21. Liu, C.W.; Hu, W.W.; Yang, B.H.; Tong, Y.; Zhu, D.M.; Zhang, L.F.; Zhao, R. N Study on the effect of metal types in (Me)-Al-MCM-41 on the mesoporous structure and catalytic behavior during the vapor-catalyzed co-pyrolysis of pubescens and LDPE. Appl. Catal. B Environ. 2013, 129, 202-213. [CrossRef]

22. Intana, T.; Föttinger, K.; Rupprechter, G.; Kongkachuichay, P. Physicochemical properties of Cu loaded onto core-shell Al-MCM-41: Effect of loading methods. Colloids Surf. A Physicochem. Eng. Asp. 2015, 467, 157-165. [CrossRef]

23. Benítez-Guerrero, M.; López-Beceiro, J.; Sánchez-Jiménez, P.E.; Pascual-Cosp, J. Comparison of thermal behavior of natural and hot-washed sisal fibers based on their main components: Cellulose, xylan and lignin. TG-FTIR analysis of volatile products. Thermochim. Acta 2014, 581, 70-86. [CrossRef]

24. Zafar, R.; Watson, J.S. Adsorption of tetradecanoic acid on kaolinite minerals: Using fast pyrolysis to characterize the catalytic efficiency of clay mineral adsorbed fatty acids. Chem. Geol. 2017, 471, 111-118. [CrossRef]

25. Souza, M.J.B.; Marinkovic, B.A.; Jardim, P.M.; Araujo, A.S.; Pedrosa, A.M.G.; Souza, R.R. HDS of thiophene over CoMo/AlMCM-41 with different Si/Al ratios. Appl. Catal. A Gen. 2007, 316, 212-218. [CrossRef]

(C) 2019 by the authors. Licensee MDPI, Basel, Switzerland. This article is an open access article distributed under the terms and conditions of the Creative Commons Attribution (CC BY) license (http://creativecommons.org/licenses/by/4.0/). 